\title{
Delayed diagnosed trauma in severely injured patients despite guidelines-oriented emergency room treatment: there is still a risk
}

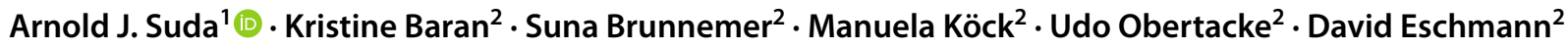

Received: 24 April 2021 / Accepted: 18 July 2021 / Published online: 29 July 2021

(c) The Author(s) 2021

\begin{abstract}
Purpose Emergency trauma room treatment follows established algorithms such as ATLS®. Nevertheless, there are injuries that are not immediately recognized here. The aim of this study was to evaluate the residual risk for manifesting lifethreatening injuries despite strict adherence to trauma room guidelines, which is different to missed injuries that describe recognizable injuries.

Methods In a retrospective study, we included 2694 consecutive patients admitted to the emergency trauma room of one single level I trauma center between 2016 and 2019. In accordance with the trauma room algorithm, primary and secondary survey, trauma whole-body CT scan, eFAST, and tertiary survey were performed. Patients who needed emergency surgery during their hospital stay for additional injury found after guidelines-oriented emergency trauma room treatment were analyzed.

Results In seven patients (0.26\%; mean age 50.4 years, range 18-90; mean ISS 39.7, range 34-50), a life-threatening injury occurred in the further course: one epidural bleeding (13 h after tertiary survey) and six abdominal hollow organ injuries (range $5.5 \mathrm{~h}-4$ days after tertiary survey). Two patients ( $0.07 \%$ overall) with abdominal injury died. The "number needed to fail" was 385 (95\%-CI 0.0010-0.0053).

Conclusion Our study reveals a remaining risk for delayed diagnosis of potentially lethal injuries despite accurate emergency trauma room algorithms. In other words, there were missed injuries that could have been identified using this algorithm but were missed due to other reasons. Continuous clinical and instrument-based examinations should, therefore, not be neglected after completion of the tertiary survey.

Level of evidence Level II: Development of diagnostic criteria on the basis of consecutive patients (with universally applied reference "gold" standard).
\end{abstract}

Keywords Missed injury $\cdot$ Delayed diagnosed injury $\cdot$ Trauma algorithm $\cdot$ ATLS $^{\circledR} \cdot$ Number needed to fail

\section{Introduction}

Arnold J. Suda

arnold.suda@auva.at

1 Department of Orthopaedics and Trauma Surgery, AUVA Trauma Center Salzburg, Academic Teaching Hospital of Paracelsus Medical University, Dr. Franz-Rehrl-Platz 5, 5010 Salzburg, Austria

2 Department of Orthopaedics and Trauma, Medical Faculty, University Medical Center Mannheim, Mannheim of Heidelberg University, Theodor-Kutzer-Ufer 1-3, 68167 Mannheim, Germany
Emergency trauma room diagnostics include structured clinical patient assessment according to guidelines provided by Advanced Trauma Life Support (ATLS ${ }^{\circledR}$ ) with mandatory procedures (blood cell count, extended Focused Assessment Sonography for Trauma (eFAST)) and potential adjuncts (X-ray, whole-body computer tomography) [1]. Some injuries need time to develop and might not be detected in the primary assessment, whereas other injuries may not be diagnosed due to other manifest injuries.

Taking this into account, the emergency trauma room physician should keep some parameters in mind for decision-making: trauma mechanism, specific lead symptoms for 
injuries, time to emergency room, hospital resources, sensitivity and specificity of diagnostic tools, prioritization of diagnostic steps, and delegation of responsibilities in rapid patient assessment.

Structured trauma training or certifications may help here to "treat first what kills first", "do no further harm", and "re-assess" [2]. Whole-body CT scan can be used to identify brain injuries, but there are insufficiencies in abdominal injury diagnostics [3, 4]. Extended fast assessment sonography for trauma (eFAST) can identify thoracic and abdominal pathologies [5, 6].

In 2018, data from the German Trauma Registry revealed that in $79.5 \%$ of cases, a whole-body CT scan was performed on severely injured patients [7]. There are no mandatory requirements, but widely accepted emergency room treatment procedures include time management, emergency room equipment (including sonography and CT scan), personnel training standards, and a structured survey. In 2009, HuberWagner et al. showed the life-saving impact of whole-body CT scan and determined that the "number needed to scan" to identify one more survivor was 17 [8]. Early total care and damage control surgery/orthopedics were influenced by this publication [9]. Missed injury is most commonly defined as an injury missed at initial assessment up to $24 \mathrm{~h}$, including primary and secondary surveys and emergency intervention [10].

Hajibandeh et al. recommend differentiating between the terms "missed injury detection rate" and "missed injury rate". [11] Keijzers et al. defined "Delayed Diagnosed Injuries" (DDI) type I for DDI found during the tertiary survey, type II for DDI found during admission, but after tertiary survey and type III for "DDI found after discharge" [10]. Ferree et al. recommend similar wording and Tammeling et al. extend this with type 0 (diagnosis before tertiary survey) $[12,13]$.

The National trauma database of the American College of Surgeons defines "missed injury" as an injury-related diagnosis discovered after the initial workup is completed and the admission diagnosis is determined [2]. Risk factors for missed injuries are higher Injury Severity Score ISS [14], altered mental status, intubation, need for intensive care, and emergency surgery $[12,15-17]$. Therefore, $X$-rays must be carefully reviewed, any examination that is not clear must be repeated, and serial examinations should be continued for the entire clinical course. Delayed injuries can be found in peripheral extremity regions such as the feet and hands $[12,18,19]$ but also in the abdomen and cranium $[11,13]$.

According to Pfeifer and Pape (2008) primary missed injuries occur in a mean of $10 \%(1.3-39 \%)$ of presenting cases [20]. Tertiary survey reduces the incidence of missed injuries and can be used as an indicator for diagnostic quality. However, there is no clear timepoint for this examination [2, 11-13, 16, 21, 22].
Schneck et al. showed a delayed diagnosis of abdominal injuries of between $0.9 \%$ and $5 \%$, mostly without any therapeutic consequences [23, 24].

ATLS $^{\circledR}$ guidelines are widely accepted. Over-triage is known to be superior, and performing a tertiary survey is mandatory to identify intracranial or intra-abdominal bleeding [1] .

Repeated brain CT scan in intubated patients and repeated abdominal sonography in all patients can be recommended as part of further clinical examination, but an exact point of time for this cannot be given. Six hours after admission is widely used but is not evidence-based.

Injuries that occur after a second CT scan or sonography are in the group of remaining risk.

The aim of this study was to identify the number needed to fail (NNF): what is the risk rate of suffering from a lifethreatening body cavity injury despite having a negative structured trauma-room treatment, including whole-body CT scan and tertiary survey? How many treatments are necessary to manifest this risk in one single patient?

\section{Patients and methods}

In this retrospective study, we included all patients who were admitted to the emergency trauma room of a level-I university trauma center over a 4-year period (January 2016 and December 2019). All patients received inpatient treatment with clinical assessment according to ATLS $^{\circledR}$ (primary, secondary, tertiary survey), blood cell count, eFAST, repeat eFAST and, dependent on the injury pattern, radiological examination or whole-body CT scan for trauma except for patients who were pregnant, young children or suffered from obvious single-site injury. Data sets from the electronic hospital information system (SAP), including radiological data of patients who received inpatient treatment, were evaluated. We excluded patients with insufficient data sets or outpatient treatment. Patients who needed emergency surgery during their hospital stay for additional injury found during emergency trauma room treatment were identified and analyzed. The remaining risk for life-threatening injuries and numbers needed to treat, fail or harm were calculated.

Statistical analysis with demographic data analysis, Student's $t$ test and Chi-square test was performed using SPSS (Version 24.0), a $p$ value $<0.05$ was defined as statistically significant.

The regional and institutional ethical committee approved the study (MA-2020-801R).

\section{Results}

3124 patients (1034 females, 2090 males, 67\%) were admitted to the emergency trauma room at University Medical Center Mannheim, Germany, between January 2016 and 
December 2019 (mean age 44 years, range 0-99). 2694 patients received inpatient treatment with clinical assessment according to ATLS ${ }^{\circledR}$ (primary, secondary, tertiary survey), whole-body CT scan for trauma (except 367 patients $=13 \%$ who were pregnant, young children or suffered from obvious single-site injury), eFAST and repeat eFAST. 430 patients received outpatient treatment for minor injuries and were not re-admitted to hospital, and 125 of them (29\%) did not receive a whole-body CT scan. Reasons were: obvious isolated injury (brain injury), clinical absence of trauma symptoms in pregnant females, adolescents or children after low energy trauma, inpatient treatment with re-assessment, immediate emergency surgery, and death in the emergency room.

176 patients $(6.6 \%)$ died in the period up to $8 \mathrm{~h}$ after admission. 110 patients (4.08\%) showed an intra-abdominal injury (AIS $>2$ ), 7 of them died in the period up to $48 \mathrm{~h}$ after admission due to severe vessel injury. Of these 110 patients, $102(92.7 \%)$ experienced blunt trauma, 66.3\% in motor vehicle accidents. Overall, 17 patients suffered from bowel or mesentery injuries due to blunt abdominal trauma (incidence $=0.63 \%$ ). We identified 83 injuries of parenchymatic organs (spleen, liver, kidney, and pancreas), 15 intra-abdominal vessel injuries, and 18 hollow organ (bowel, stomach, and bladder) and mesentery injuries. Two small bowel injuries occurred in penetrating trauma. We found severe brain trauma $(\mathrm{GCS}<12$, emergency surgery, AIS $>2$ ) in 368 patients (13.66\%), 111 of them (30.16\%) died within $48 \mathrm{~h}$ after admission.

Seven patients $(0.26 \%$; mean age 50.4 years, range $18-90$, 2 females, 5 males; mean ISS 33.7, range 17-50) underwent delayed emergency surgery due to an injury that was not identified despite a correct emergency trauma room algorithm including imaging and admission to ICU. Six of these patients showed intra-abdominal injury, one an epidural bleeding (Table 1). Patients 1 and 6 showed hemodynamic instability within the first two hours after finishing the tertiary survey, which led to intubation. In a repeat eFAST, new intra-abdominal free fluid could be identified and explorative laparotomy was performed. Patient 6 (90 years) did not survive. Neither patient could be classified according to Kejzers' DDI [10].

In patient 2 (awake, DDI type I), abdominal pain occurred after $24 \mathrm{~h}$ and further diagnostics and therapy could be initiated. In patient 7 (awake, DDI type I), nausea and vomiting led to a repeat CT scan of the brain $13 \mathrm{~h}$ after admission and intra-cerebral bleeding could be identified and treated surgically. In patients 3,4 , and 5 (DDI type II), clinical manifestation of perforated hollow organ was delayed significantly: Patient 3 showed rising signs of infection in the blood cell count but without clinical signs of acute abdomen. After 3 days, a repeat CT scan of the abdomen was performed, and free intra-abdominal fluid was diagnosed with known presence of pelvic fracture and hematoma. Another CT scan after 8 days showed contrast fluid leakage, and explorative laparotomy was performed but at this time with signs of severe sepsis. The patient died. Patient 4 (awake, traumatic spinal cord injury with complete thoracal paraplegia) showed signs of acute abdomen on day 2 and free intra-abdominal fluid in a repeat eFAST. In re-CT of the abdomen, bowel perforation could be seen and treated. Patient 5 (awake, spleen injury, conservative treatment) did not show clinical remission over 6 days. A repeat CT scan showed free intra-abdominal fluid. Both patients who died had a high injury severity score (ISS 48 and 50) and higher age (73 and 90). The remaining risk for patients in our cohort was $0.26 \%$ (95\%-CI 0.0010-0.0053), the "number needed to fail" was 385 .

\section{Discussion}

The acute diagnostic safety of hollow organ injuries in emergency trauma room according to guidelines is high: the structured trauma assessment only failed to identify life-threatening injury in 7 of 2694 patients. Two of the 7 patients died. All cases of abdominal injuries showed bowel perforation. All 7 patients were treated in hospital. Missed or delayed diagnosed injuries are known, but to our knowledge, this is the first study to quantify the remaining risk of life-threatening injuries, which is different from missed or delayed diagnosed injuries.

Under- and over-triage or over-diagnostics with the inclusion of too many patients in an emergency trauma room algorithm has recently been discussed. However, no changes of algorithms or guidelines have been implemented so farunder-triage of 5\% and over-triage of 25-35\% are stated as acceptable, and more than $25 \%$ of "too many" alarms should be tolerated [25]. Huber-Wagner et al. mentioned a number needed to treat of 17 for whole-body CT scan: 17 patients need to be investigated to save one patient's life [8]. German trauma registry data shows $11.4 \%$ overall lethality [7]. Only a retrospective study design in a large cohort treated with exactly the same algorithm can identify any remaining risks. In a prospective setting, the presence of any injury could be suspected in a tertiary survey, and a bias would be created. Although whole-body trauma CT scan is widely used, clinical examination according to a guideline-related algorithm is crucial. Overall, hollow organ injuries in blunt abdominal trauma are relatively rare, with rates of between $2.9 \%$ and 5\% [26-28]. Lawson et al. analyzed 26,264 trauma patients and found 90 patients $(0.34 \%)$ with delayed diagnosis [29]. Most missed injuries were bowel and mesentery $(16,17 \%$ : mostly present on day 2 after admission). Small bowel injuries show slow and occult presentation with peritonitis leading to sepsis in some cases: other patients survive [30]. 


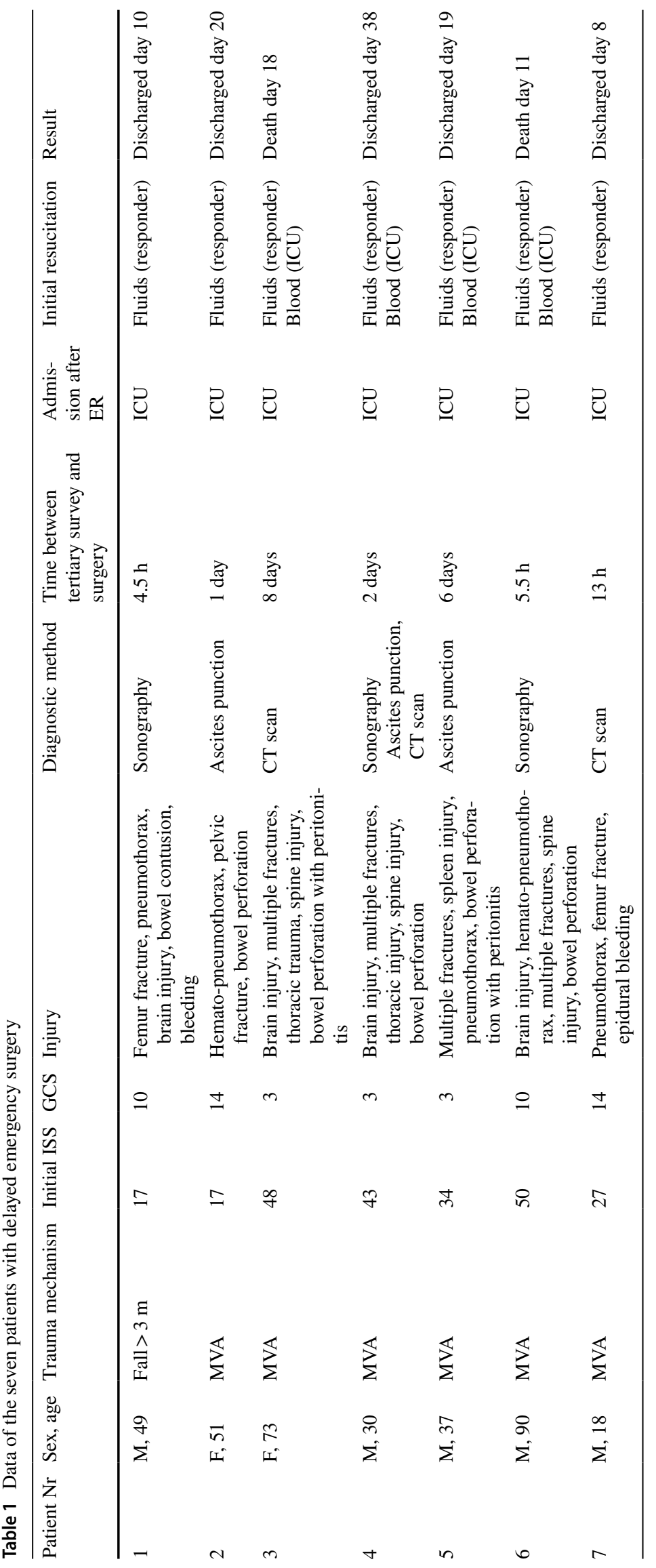


Especially in blunt abdominal trauma, bowel injuries lead to increased morbidity and mortality. The risk of "missed injury" is higher in blunt compared to penetrating abdominal trauma [31-33]. In 2000, Fakhry et al. reported 198 patients with 9 dead due to delayed diagnosed small bowel perforations (SMP) [28]. In 2019, the same authors presented a study of 127,919 trauma patients with 77 suffering from SBP (incidence $0.06 \%, 8.43 \mathrm{~h}$ to surgical intervention). One patient died, the mortality rate was $1.4 \%$, and longer time to surgery was correlated to mortality [34]. Clinical assessment without whole-body CT trauma scan led to false-negative laparotomies and diagnostic peritoneal lavage of up to $40 \%$ in the past: several authors concluded that laparotomy is not mandatory in patients with intra-abdominal free fluid in CT scan and blunt abdominal trauma without injury of parenchymatous organs $[26,35,36]$. In these cases, clinical re-assessment and a repeat CT scan is recommended [37]. Scaglione and others recommended clinical observation, monitoring, surgical expertise, and CT scan for the decisionmaking process in patients with blunt abdominal trauma [37-39]. Yoong et al. found high sensitivity of whole-body CT scan with a missed injury rate of $2.4 \%$ [40].

In our study, the residual risk appears between several hours and 8 days after hospital admission. Intubation or reduced vigilance were not risk factors, and high ISS was associated with higher mortality. Re-evaluation is the key to catching all injuries. We could not identify any suggestions for improvement regarding therapy or diagnostics. The low mortality rate is related to central Europe, modern technical equipment, low mass casualty rates, and low gunshot/stab wound injury rates.

We recommend classifying missed injuries in

Delayed diagnosed injuries DDI

$$
\begin{aligned}
& A=\text { after trauma room treatment } \\
& B=\text { during tertiary survey } \\
& C=\text { after tertiary survey until discharge from hospital }
\end{aligned}
$$

\section{With subgroups}

(1) potentially life-threatening

(2) therapeutically relevant injuries

(3) facultative relevant injuries

All patients with manifest risk in our study were only classified as B1 and $\mathrm{C} 1$.

We cannot recommend a certain point of time for the tertiary survey based on our data. However, a repeated eFAST or CT scan is not an alternative for a correct clinical reassessment, as described in the tertiary survey.

In our study, all seven detected patients showed ISS $>16$ and initially diagnosed spinal cord injury, spleen rupture, or pelvis fracture might have led to distraction compared to other injuries even there was no sign of injury in initial clinical and instrument-based diagnostics.
Author contributions All authors contributed to the study conception and design. Material preparation, data collection, and analysis were performed by KB and SB. The first draft of the manuscript was written by AJS and all authors commented on previous versions of the manuscript. All authors read and approved the final manuscript. Conceptualization: UO, MK, and AJS; methodology: UO, KB, and AJS; formal analysis and investigation: $\mathrm{KB}, \mathrm{UO}$, and AJS; writing-original draft preparation: $\mathrm{KB}$ and AJS; writing-review and editing: AJS, KB, and UO; resources: DE and AJS; and supervision: AJS, DE, and UO.

Funding Open Access funding enabled and organized by Projekt DEAL. The authors did not receive support from any organization for the submitted work. No funding was received to assist with the preparation of this manuscript. No funding was received for conducting this study. No funds, grants, or other support was received.

Availability of data and materials With corresponding author due to ethical committee vote.

Code availability Not applicable.

\section{Declarations}

Conflicts of interest The authors have no relevant financial or nonfinancial interests to disclose. The authors have no conflicts of interest to declare that are relevant to the content of this article. All authors certify that they have no affiliations with or involvement in any organization or entity with any financial interest or non-financial interest in the subject matter or materials discussed in this manuscript. The authors have no financial or proprietary interests in any material discussed in this article.

Ethics approval The study was approved by the regional and institutional ethical committee and the authors certify that the study was performed in accordance with the ethical standards as laid down in the 1964 Declaration of Helsinki and its later amendments or comparable ethical standards.

Consent to participate Not applicable due to ethical committee vote.

Consent for publication Not applicable due to ethical committee vote.

Open Access This article is licensed under a Creative Commons Attribution 4.0 International License, which permits use, sharing, adaptation, distribution and reproduction in any medium or format, as long as you give appropriate credit to the original author(s) and the source, provide a link to the Creative Commons licence, and indicate if changes were made. The images or other third party material in this article are included in the article's Creative Commons licence, unless indicated otherwise in a credit line to the material. If material is not included in the article's Creative Commons licence and your intended use is not permitted by statutory regulation or exceeds the permitted use, you will need to obtain permission directly from the copyright holder. To view a copy of this licence, visit http://creativecommons.org/licenses/by/4.0/.

\section{References}

1. Galvagno SM Jr, Nahmias JT, Young DA. Advanced trauma life support((R)) Update 2019: management and applications for adults and special populations. Anesthesiol Clin. 2019;37:13-32.

2. Enderson BLRD, Meadors J, et al. The tertiary trauma survey: a prospective study of missed injury. J Trauma. 1990;30:666-70. 
3. Hefny AF, Kunhivalappil FT, Matev N, Avila NA, Bashir MO, Abu-Zidan FM. Usefulness of free intraperitoneal air detected by CT scan in diagnosing bowel perforation in blunt trauma: Experience from a community-based hospital. Injury. 2015;46:100-4.

4. Marek AP, Deisler RF, Sutherland JB, Punjabi G, Portillo A, Krook J, Richardson CJ, Nygaard RM, Ney AL. CT scan-detected pneumoperitoneum: An unreliable predictor of intra-abdominal injury in blunt trauma. Injury. 2014;45:116-21.

5. Grüessner RMB, Düber C, Rückert K, Rothmund M. Sonography versus peritoneal lavage in blunt abdominal trauma. J Trauma. 1989;29:242-4.

6. Hauenstein KH WB, Billmann P, Nöldge G, Zavisic D [Sonography of blunt abdominal trauma (author's transl)]. 1982;22(3):106-111.

7. NIS Annual report of TraumaRegister DGU. In: AUC (ed). 2019. Köln, Germany. p. 68.

8. Huber-Wagner S, Lefering R, Qvick LM, Körner M, Kay MV, Pfeifer KJ, Reiser M, Mutschler W, Kanz KG. Effect of wholebody CT during trauma resuscitation on survival: a retrospective, multicentre study. Lancet. 2009;373:1455-61.

9. Pfeifer R, Pape HC. [Diagnostics and treatment strategies for multiple trauma patients]. Chirurg. 2016;87:165-73 (quiz 174-165).

10. Keijzers GB, Giannakopoulos GF, Del Mar C, Bakker FC, Geeraedts LMG. The effect of tertiary surveys on missed injuries in trauma: a systematic review. Scand J Trauma Resusc Emerg Med. 2012;20:77.

11. Hajibandeh S, Hajibandeh S, Idehen N. Meta-analysis of the effect of tertiary survey on missed injury rate in trauma patients. Injury. 2015;46:2474-82.

12. Ferree S, Houwert RM, van Laarhoven JJ, Smeeing DP, Leenen LP, Hietbrink F. Tertiary survey in polytrauma patients should be an ongoing process. Injury. 2016;47:792-6.

13. Tammelin E, Handolin L. Soderlund T missed injuries in polytrauma patients after trauma tertiary survey in trauma intensive care unit. Scand J Surg. 2016;105:241-7.

14. Baker SP, O'Neill B, Haddon W Jr, Long WB. The injury severity score: a method for describing patients with multiple injuries and evaluating emergency care. J Trauma. 1974;14:187-96.

15. Buduhan G, McRitchie DI. Missed injuries in patients with multiple trauma. J Trauma. 2000;49:600-5.

16. Biffl WL, Harrington DT, Cioffi WG. Implementation of a tertiary trauma survey decreases missed injuries. J Trauma. 2003;54:38-43.

17. Furnival RA, Woodward GA, Schunk JE. Delayed diagnosis of injury in pediatric trauma. Pediatrics. 1996;98:56-62.

18. Giannakopoulos GF, Saltzherr TP, Beenen LF, Reitsma JB, Bloemers FW, Goslings JC, Bakker FC. Missed injuries during the initial assessment in a cohort of 1124 level-1 trauma patients. Injury. 2012;43:1517-21.

19. Brooks A, Holroyd B, Riley B. Missed injury in major trauma patients. Injury. 2004;35:407-10.

20. Pfeifer R, Pape H-C. Missed injuries in trauma patients: A literature review. Patient Safety Surg. 2008;2:20-20.

21. Vles WJ, Veen EJ, Roukema JA, Meeuwis JD, Leenen LP. Consequences of delayed diagnoses in trauma patients: a prospective study. J Am Coll Surg. 2003;197:596-602.

22. Keijzers GB, Giannakopoulos GF, Del Mar C, Bakker FC, Geeraedts LMG. The effect of tertiary surveys on missed injuries in trauma: a systematic review. Scand J Trauma Resusc Emerg Med. 2012;20:77.

23. Schneck E, Koch C, Borgards M, Reichert M, Hecker A, Heiss C, Padberg W, Alejandre-Lafont E, Rhrig R, Krombach G, Weigand M, Bernhard M, Roller F. Impact of Abdominal Follow-Up Sonography in Trauma Patients Without Abdominal Parenchymal Organ Lesion or †Free Intraabdominal Fluid in Whole-Body
Computed Tomography. RoFo Fortschritte auf dem Gebiete der Rontgenstrahlen und der Nuklearmedizin. 2017;189(2):128-36.

24. Paydar S, Dalfardi B, Zangbar-Sabegh B, Heidaripour H, Pourandi L, Shakibafard A, Tahmtan M, Shayan L, Niakan MH. The predictive value of repeated abdominal ultrasonography in patients with multiple trauma and decreased level of consciousness: the experience of a resource-limited centre. Bull Emerg Trauma. 2018;6:26-30.

25. Surgeons ACo Resources for optimal care of the injured patient. 2014. American College of Surgeons, 633 N. Saint Clair St., Chicago, IL 60611-3211.

26. Bekker W, Kong VY, Laing GL, Bruce JL, Manchev V, Clarke DL. The spectrum and outcome of blunt trauma related enteric hollow visceral injury. Ann R Coll Surg Engl. 2018;100:290-4.

27. Bloom AI, Rivkind A, Zamir G, Gross E, Kluger Y, Reissman P, Muggia-Sullam M. Blunt injury of the small intestine and mesentery-the trauma surgeon's Achilles heel? Eur J Emerg Med. 1996;3:85-91.

28. Fakhry SM, Brownstein M, Watts DD, Baker CC, Oller D Relatively short diagnostic delays ( $<8$ hours) produce morbidity and mortality in blunt small bowel injury: an analysis of time to operative intervention in 198 patients from a multicenter experience. $\mathbf{J}$ Trauma. 2000;48:408-414; discussion 414-405.

29. Lawson CM, Daley BJ, Ormsby CB, Enderson B. Missed injuries in the era of the trauma scan. J Trauma. 2011;70:452-6 (discussion 456-458).

30. Hamidian Jahromi A, Johnson L, Youssef AM. Delayed small bowel perforation following blunt abdominal trauma: A case report and review of the literature. Asian J Surg. 2016;39:109-12.

31. Sommers MS. Missed injuries: a case of trauma hide and seek. AACN Clin Issues. 1995;6:187-95.

32. Scalea TM, Phillips TF, Goldstein AS, Sclafani SJ, Duncan AO, Atweh NA, Shaftan GW. Injuries missed at operation: nemesis of the trauma surgeon. J Trauma. 1988;28:962-7.

33. Arslan S, Okur MH, Arslan MS, Aydogdu B, Zeytun H, Basuguy $\mathrm{E}$, Icer M, Goya C. Management of gastrointestinal perforation from blunt and penetrating abdominal trauma in children: analysis of 96 patients. Pediatr Surg Int. 2016;32:1067-73.

34. Fakhry SM, Allawi A, Ferguson PL, Michetti CP, Newcomb AB, Liu C, Brownstein MR. Group EsbpM-CS Blunt small bowel perforation (SBP): An Eastern Association for the Surgery of Trauma multicenter update 15 years later. J Trauma Acute Care Surg. 2019;86:642-50.

35. Rodriguez C, Barone JE, Wilbanks TO, Rha CK, Miller K. Isolated free fluid on computed tomographic scan in blunt abdominal trauma: a systematic review of incidence and management. J Trauma. 2002;53:79-85.

36. Gonser-Hafertepen LN, Davis JW, Bilello JF, Ballow SL, Sue LP, Cagle KM, Venugopal C, Hafertepen SC, Kaups KL. Isolated free fluid on abdominal computed tomography in blunt trauma: watch and wait or operate? J Am Coll Surg. 2014;219:599-605.

37. Brofman N, Atri M, Hanson JM, Grinblat L, Chughtai T, Brenneman F. Evaluation of bowel and mesenteric blunt trauma with multidetector CT. Radiographics. 2006;26:1119-31.

38. Scaglione M. Emergency radiology special feature: editorial. $\mathrm{Br}$ J Radiol. 2016;89:20160203.

39. Cinquantini F, Tugnoli G, Piccinini A, Coniglio C, Mannone S, Biscardi A, Gordini G. Di Saverio S Educational Review of Predictive Value and Findings of Computed Tomography Scan in Diagnosing Bowel and Mesenteric Injuries After Blunt Trauma: Correlation With Trauma Surgery Findings in 163 Patients. Can Assoc Radiol J. 2017;68:276-85.

40. Yoong S, Kothari R, Brooks A. Assessment of sensitivity of whole body CT for major trauma. Eur J Trauma Emerg Surg. 2019;45:489-92. 